\title{
GEOFILOSOFIA E ANTROPOFAGIA: Esboço de leitura deleuzo-guattariana do pensamento modernista de Oswald de Andrade ${ }^{1}$
}

Paulo Domenech Oneto

RESUMO:

Recorrendo à geofilosofia proposta por Deleuze e Guattari, particularmente aos conceitos de terra e território, o artigo procura refletir sobre a antropofagia de Oswald de Andrade analisando-o como uma estratégia de invenção social ou de produção de subjetividade.

Palavras-chave: geofilosofia; antropofagia; Oswald de Andrade;

\footnotetext{
${ }^{1}$ Comunicação apresentada no Colloque Brésil-Europe, organizado pelo Collège International de Philosophie em setembro de 2008. Tradução de Silvia Pimenta.
} 
Aquilo que me proponho a fazer nesta breve apresentação pode parecer muito ambicioso, mas o objetivo é simplesmente apresentar o estado atual de minhas pesquisas sobre o pensamento modernista de Oswald de Andrade. Essas pesquisas se inscrevem em um quadro mais amplo onde se busca traçar um paralelo entre dois momentos da literatura do «novo mundo», a saber: um momento que poderíamos denominar pós-romântico da literatura norte americana (por volta da segunda metade do século XIX), com Walt Whitman e Herman Melville, e um outro momento, autointitulado modernista e antropófago, que é precisamente o de Oswald de Andrade, no Brasil, na segunda década do século XX. A ideia que anima e parece autorizar um tal paralelo é a seguinte: nos dois casos, a despeito das diferenças de intenção, temas, estilos e épocas, trata-se de propor ou de desenvolver - de modo explícito ou implícito estratégias de invenção social.

Mas em que sentido podemos falar de estratégias de invenção social nos casos citados? Sobretudo, como compreender a antropofagia oswaldiana a partir de tais termos?

A segunda pergunta é o próprio tema deste texto, mas ela parece estar subordinada à primeira, cuja resposta permite esclarecer o título que escolhi para minha apresentação. Por "estratégias de invenção social" entendo, mais precisamente, esse esforço das artes (particularmente na modernidade) de contribuir para a "invenção de um povo" 2 , tendo como gesto filosófico de base "invocar uma nova terra, a um novo povo" (DELEUZE e GUATTARI, 1992, p. 127), ou ainda a tentativa literária de sempre fazer "fugir algo na linha de horizonte [...] tentando perfurar o muro, retomando a experimentação, encontrando uma fraternidade nesse empreendimento» (DELEUZE, 1997, p. 102), segundo as palavras de Gilles Deleuze, escrevendo sozinho ou em colaboração com Félix Guattari.

A meu ver, as três fórmulas citadas convergem para a noção de geofilosofia. Trata-se, portanto, de utilizar o pensamento de Deleuze ou de Deleuze-Guattari como grade de leitura, ou melhor, como "caixa de ferramentas" para procurar compreender a

\footnotetext{
22005 , p. 206 “é um devir, ele se inventa, nas favelas ou nos campos, ou nos guetos, com novas condições de luta, para as quais uma arte verdadeiramente política deve contribuir”.
} 
questão da antropofagia oswaldiana e não, evidentemente, para confirmá-la. Dito de outro modo, não se deve ver neste texto um esforço para fazer coincidir a ideia antropofágica com a geofilosofia proposta por Deleuze-Guattari. Deixo de lado também os aspectos da literatura americana porque não estão diretamente ligados ao problema da «deglutição do outro».

De todo modo, deve-se precisar desde já que considero aqui a ideia antropofágica de Oswald de Andrade em termos de estratégia de invenção social ou de produção de subjetividade, para além do interesse especificamente estético que possa suscitar. No entanto, a meu ver as duas coisas permanecem ligadas, e eu as aproximo da seguinte maneira: um manifesto estético tem como objetivo primordial a produção de uma nova sensibilidade por meio de uma nova maneira de pensar as artes. Ao fazê-lo, implica numa certa análise das condições nas quais tal pensamento pode emergir e produzir efeitos. Quanto mais um manifesto estético se volta para a questão do lugar no qual se busca criar os agregados sensíveis próprios às diversas artes, e no qual se busca afetar as pessoas, mais ele consiste numa estratégia de invenção social.

É justamente o caso dos dois manifestos de Oswald de Andrade publicados nos anos 1920 - «Pau-Brasil» e «Antropófago». Entretanto, não pretendo retornar às palavras exatas do manifesto nem expor o contexto no qual foram produzidos - outros palestrantes já o fizeram. O que vou tentar fazer é mostrar brevemente como a estratégia modernista oswaldiana de produção de subjetividade e de invenção social de uma comunidade ressoa com a geofilosofia de Deleuze-Guattari, ou como pode a partir desta ser compreendida; em seguida, procurarei superar o que vejo como preconceitos sobre a ideia de antropofagia. Vou procurar concluir com o esboço de um diagnóstico do presente.

Três momentos, portanto: um primeiro momento mais filosófico, que consiste em apresentar as ferramentas deleuzo-guattarianas; um segundo momento para ajudar Oswald e o manifesto antropófago a escapar das frequentes acusações de idealizador de uma sociedade primitiva, simplificador nacionalista, pregador da assimilaçãoeliminação das diferenças étnicas, ou mesmo defensor da mestiçagem compreendida como mistura pacífica de todas as etnias - no estilo: «não há racismo no Brasil porque somos todos mestiços, negros, mulatos, indígenas, sei lá o que mais»; enfim, um 
terceiro momento, para diagnosticar o estado atual de nossa produção de subjetividade no Brasil e no chamado primeiro mundo.

Abordo a primeira etapa com uma citação de Deleuze-Guattari no capítulo 4 («Geofilosofia») de O que é a filosofia?:

Pensar não é um fio estendido entre um sujeito e um objeto, nem uma revolução de um em torno do outro. Pensar se faz na relação entre o território e a terra (...). Vimos, todavia, que a terra não cessa de operar um movimento de desterritorialização in loco, pelo qual ultrapassa todo território: ela é desterrítorializante e desterritorializada (...). Os movimentos de desterritorialização não são separáveis dos territórios que se abrem sobre um alhures, e os processos de reterritorialização não são separáveis da terra que restitui territórios. (1992, p. 113)

Antes de mais nada, temos que ver o que os autores entendem por esses dois termos. Trata-se, com certeza, de afirmar o meio no qual um pensamento pode emergir e ser partilhado, evidentemente não em termos de seus conteúdos, mas em seu modo de operação. Assim, por exemplo, é possível descobrir caracteres nacionais em um pensamento de tipo filosófico, literário ou artístico, mesmo se o que lhe é essencial não cessa de ultrapassar esses limites. A tentativa nietzschiana de determinar os caracteres nacionais da filosofia francesa, inglesa e alemã está, nesse sentido, longe de ser um movimento de redução dessas filosofias ao território de onde elas, por assim dizer, brotam. É por isso que Deleuze-Guattari podem escrever, numa passagem do mesmo livro:

É sempre em conformidade com o espírito de um povo e sua concepção do direito que a filosofia se reterritorializa no mundo moderno. A história da filosofia é, pois, marcada por caracteres nacionais ou, antes, nacionalitários, que são como "opiniões" filosóficas. (1992, p. 134)

Mas a filosofia não é feita unicamente de «opiniões» filosóficas, assim como a história da filosofia permanece incapaz de compreender esse movimento de criação conceitual que - segundo Deleuze-Guattari - caracteriza o pensamento filosófico. Poderíamos dizer o mesmo sobre a literatura e as artes. Elas não são feitas apenas de opiniões. Suas histórias são, em última instância, incapazes de recobrir seus devires insuspeitados. 
Por que isso? E qual a relação disso com a antropofagia oswaldiana?

Vejamos o que Deleuze-Guattari dizem mais exatamente sobre essa relação entre o território e a terra para, enfim, compreender o alcance dos termos.

Cito mais uma vez:

A geografia não se contenta em fornecer uma matéria e lugares variáveis para a forma histórica. Ela não é somente física e humana, mas mental, como a paisagem. Ela arranca a história do culto da necessidade, para fazer valer a irredutibilidade da contingência. Ela a arranca do culto das origens, para afirmar a potência de um "meio" (...). Ela a arranca das estruturas, para traçar as linhas de fuga (...). Enfim, ela arranca a história de si mesma, para descobrir os devires, que não são a história, mesmo quando nela recaem (...)”. (1992, pp. 124/125)

Como eu dizia há pouco, trata-se efetivamente de afirmar o meio no qual o pensamento pode emergir e ser partilhado, mas esse meio não se define apenas por traços físicos sem passar pela mente, que - como a passagem citada parece indicar designa o próprio território («paisagem»). Ocorre que esse território mental não cessa de ser arrancado de si mesmo ou, dito de outro modo, não cessa de mudar em função do que produz em termos de pensamento ou de subjetividade. Assim, as explicações enigmáticas propostas por Deleuze-Guattari logo no início do capítulo 4, citadas acima, tornam-se claras. A terra não é nada mais que esse elemento que vem de fora para arrancar o território de si mesmo, permitindo assim uma desterritorialização a partir da qual o meio ou a atmosfera já não pode mais se reconhecer. Consequentemente, os caracteres nacionais de um pensamento - seja ele filosófico, literário ou artístico tendem a ser ultrapassados.

No entanto, isso parece permanecer ainda um tanto abstrato. O que é essa terra que vem de fora? O que é esse fora, afinal?

É aqui que podemos fazer intervir a ideia oswaldiana de antropofagia. Já no Manifesto Antropófago de 1928, Oswald fala de comunicação com o solo em oposição ao que seria da ordem do meramente vegetal. Bem mais tarde em sua trajetória intelectual, após uma fase de intensas leituras filosóficas (em meados dos anos 1940), numa tentativa de definir melhor a antropofagia, Oswald fala da terra do novo mundo como «lama profunda e fértil», capaz ao mesmo tempo de filtrar os caracteres dos 
artistas e de se deixar exprimir por esses mesmos caracteres. Tudo indica que se trata de um retorno ao solo.

Pois bem, a partir daí, creio que é possível avançar a seguinte hipótese: a ideia modernista e oswaldiana de deglutição ou devoração do outro - essa «única lei do mundo» de acordo com as palavras do manifesto - está longe de significar que o elemento local deve engolir e digerir o elemento estrangeiro. Trata-se antes de afirmar a necessidade de nos voltarmos para aquilo que nos compõe - o solo enlameado em que cresce o vegetal, a matéria trabalhada pelos artistas e que lhes possibilita mudar. Nesse sentido, «comer» o europeu, como faziam os Tupinambás, não é de modo algum uma operação de assimilação que conduziria a um ajuste entre as diferenças, mas o ato pelo qual poderíamos, enquanto sujeitos de um meio ou de um território mental, descobrir outras possibilidades de vida a partir do encontro com o outro, que aparece aqui como uma espécie de limite de nossa imagem identitária.

A meu ver, é justamente isso que significa a noção de «terra» de DeleuzeGuattari. Em resumo, a terra é esse elemento que nos permite mudar, a lama com a qual entramos em contato paradoxalmente por intermédio do outro, inseparável dos - e irredutível aos - territórios ou meios relativos que se formam (territorialização) e que, justamente, não cessam de ser arrancados de si mesmos (desterritorialização).

Entretanto, como mostram Deleuze-Guattari, há ainda mais a levarmos em consideração. Há, segundo eles, desterritorializações relativas e absolutas. As primeiras são de ordem física, psicológica ou social, e concernem situações históricas; ao passo que as desterritorializações absolutas ocorrem a cada vez que esta terra - a lama oswaldiana que nos constitui, mas que só nos chega a partir do encontro com o outro - é engendrada por um gesto de pensamento, num ato de criação, como num manifesto: os de Oswald, por exemplo.

Teria Oswald conseguido produzir tal tipo de desterritorialização absoluta por meio de seus manifestos Pau-Brasil e Antropófago, entendidos como manifestos pela desterritorialização? Dito de outro modo, o modernismo brasileiro terá sido capaz de produzir uma mudança subjetiva nisso que denominamos «Brasil»?

Não sei. Aparentemente sim e não. 
Sim, na medida em que modernismo oswaldiano conheceu importantes retomadas no plano social ou artístico. Mas não, na medida em que essas mudanças permaneceram, talvez, modestas, localizadas, foram ignoradas e às vezes até mesmo silenciadas. Para retomar mais uma fórmula de Deleuze-Guattari: não, pois as desterritorializações relativas da sociedade brasileira não chegaram a ser voltadas contra si mesmas para invocar uma nova forma de sociabilidade e produzir uma subjetividade nova. Pois infelizmente, creio que o Brasil permanece, por exemplo, um país fundamentalmente racista, com hierarquias bem marcadas, apesar da camuflagem do «jeitinho»e da famosa malandragem analisada por pensadores importantes como Antônio Cândido. Trata-se de uma sociedade em que reina um estranho sistema de mediações (o célebre «favor», denunciado por Roberto Schwarz em seu ensaio sobre Machado de Assis) que ajuda a mascarar tudo isso que nos avilta.

Tendemos, então, a passar a imagem de uma cordialidade encarada como signo de delicadeza e simpatia, quando este absolutamente não era o único sentido dado ao termo, segundo a célebre tese de Sergio Buarque de Holanda em Raízes do Brasil tratava-se para este sociólogo de mostrar que a sociedade brasileira sempre colocou as relações afetivas acima da política. O que chamo em minha segunda tese de doutoramento de "nosso complexo de Antígona". Apresentamo-nos ainda o país como um lugar de mestiçagem pacífica quando esta foi sempre uma violenta linha de fuga dos modelos identitários oriundos da Europa ou criados in loco para justificar uma ordem social completamente desigual.

O projeto oswaldiano não é de modo algum, a meu ver, um projeto de mestiçagem nesses termos. Para evitar tal idealização, deve-se encontrar um novo termo, talvez como aquele proposto pelo artista oiticiquiano Edson Barrus em sua intervenção neste colóquio: «mulatação». Nesse caso, deveríamos ver no processo de mistura étnica não um acordo consensual entre os grupos étnicos - do gênero «viva a diferença!», mas sim um verdadeiro processo antropofágico pelo qual é preciso se confrontar com o outro para descobrir, enfim, esta terra que nos constitui e só pode vir de fora, o que não se confunde com os territórios nacionais ou nacionalizados e com nossas imagens identitárias, modelos ou padrões.

Através desse processo antropofágico, poderíamos talvez sair de nós mesmos. Nos anos 1920 de Oswald, a questão girava em torno de ajudar a combater o complexo 
de inferioridade do Brasil das chamadas «três raças tristes» (Paulo Prado), ajudar a vencer a Europa-modelo; mas, ao mesmo tempo, inspirar-se no que os movimentos estéticos europeus podiam nos dar como limite da imagem identitária deles, europeus.

Enfim, creio que o «comer» oswaldiano, apontado como única «lei do mundo» deve ser encarado mais como uma atitude de desapropriação de si do que como a atitude oposta (apropriação do outro). Trata-se - como se verá mais tarde com a estética da fome de Glauber Rocha no cinema, com o tropicalismo no domínio da música, entre outros tantos exemplos - de se deixar confrontar aos elementos que vêm de fora e que, no entanto, nos habitam: quer sejam os negros, os «paraíbas» ou os favelados no Brasil, quer sejam os imigrantes árabes ou kosovares na França, como o artista Yann Beauvais bem apresentou em seu vídeo intitulado «Contre-feu».

Gostaria de concluir fazendo referência às palavras expressas por Jeanne-Marie Gagnebin, que ontem falava de dar continuidade ao trabalho do pensamento entre Brasil e Europa «sem nos ignorar, mas sem nos devorar».

Eu diria que, na antropofagia oswaldiana, trata-se sim de devorar o outro, mas de devorá-lo precisamente para que deixemos de nos ignorar uns aos outros e, mais fundamentalmente ainda, de ignorarmos nossa própria diferença constituinte, justamente aquilo que, para me valer das palavras de Michel Foucault, a cada momento estamos deixando de ser. 


\section{REFERÊNCIAS BIBLIOGRÁFICAS}

ANDRADE, O. A Utopia Antropofágica. In. Obras Completas. São Paulo: Ed. Globo / Secretaria de Estado da Cultura de São Paulo, 1990.

DELEUZE, G. \& GUATTARI, F. - O que é a filosofia? Rio de Janeiro: Ed. 34, 1992

DELEUZE, G. - Crítica e Clínica. Rio de Janeiro: Ed. 34, 1997

GAGNEBIN, J. M. La déglutition des différences. Comunicação apresentada no Colloque Brésil-Europe, organizado pelo Collège International de Philosophie em setembro de 2008. Disponível em http://www.ciph.org/fichiers_papiers/Papiers60.pdf 